\title{
An Accidental Repetitive 10-Fold Overdose of Sildenafil in a Young Infant with Pulmonary Hypertension
}

\author{
Laura E.J. Peeters ${ }^{a}$ b Suzan C.M. Cochius-den Otter ${ }^{c}$ Bregje C.M. Witjes ${ }^{a}$ \\ Saskia J. Gischler ${ }^{c}$ Robert B. Flint ${ }^{\mathrm{a}, \mathrm{d}}$ \\ aDepartment of Hospital Pharmacy, Erasmus MC, University Medical Center Rotterdam, Rotterdam, The \\ Netherlands; bepartment of Internal Medicine, Erasmus MC, University Medical Center Rotterdam, Rotterdam, \\ The Netherlands; ' Department of Intensive Care and Paediatric Surgery, Erasmus MC, University Medical Center \\ Rotterdam, Rotterdam, The Netherlands; ${ }^{d}$ Department of Neonatology, Erasmus MC, University Medical Center \\ Rotterdam, Rotterdam, The Netherlands
}

\section{Established Facts}

- Sildenafil is often used to treat pulmonary hypertension $(\mathrm{PH})$ in neonates.

- Efficacy and safety data of sildenafil in neonates and young infants with PH are scarce.

- There is a large inter-patient variability in plasma concentrations of sildenafil in neonates and young infants.

\section{Novel Insights}

- High-dose sildenafil in young infants do not always lead to serious adverse events and may be well tolerated.

- Therapeutic drug monitoring of sildenafil can be used to monitor symptoms and support clinical decision-making.

\section{Keywords}

Diaphragmatic hernia · Medication error · Pharmacokinetics · Sildenafil · Neonate

\begin{abstract}
Sildenafil is a selective phosphodiesterase type-5 inhibitor that is increasingly used to treat pulmonary hypertension $(\mathrm{PH})$ in neonates. Only little is known about the relation between the dose of sildenafil, plasma concentrations, and the degree of toxicity. Here, we present a young infant with con-
\end{abstract}

genital diaphragmatic hernia and $\mathrm{PH}$ who received an unintentional 10-fold overdose of oral sildenafil for 6 consecutive days. This overdose, compared to the therapeutic dose, resulted in increased plasma concentrations of sildenafil from 42 to $521 \mathrm{mcg} / \mathrm{L}$ and desmethylsildenafil from 81 to 393 $\mathrm{mcg} / \mathrm{L}$. However, the high exposure only led to diarrhea, without any other serious adverse events. This case describes the mild symptoms upon an overdose with the role of therapeutic drug monitoring to monitor exposure in relation to symptoms and therewith support clinical decisionmaking.
(C) 2021 The Author(s)

Published by S. Karger AG, Basel karger@karger.com www.karger.com/neo

Karger $\stackrel{\text { ' }}{5}$

BOPEN ACCESS
(C) 2021 The Author(s)

Published by S. Karger AG, Basel

This is an Open Access article licensed under the Creative Commons Attribution-NonCommercial-4.0 International License (CC BY-NC) (http://www.karger.com/Services/OpenAccessLicense), applicable to the online version of the article only. Usage and distribution for commercial purposes requires written permission.
Laura E.J. Peeters

Department of Internal Medicine \& Hospital Pharmacy Erasmus University Medical Center

Postbus 2040, NL-3000 CA Rotterdam (The Netherlands)

l.e.j.peeters@erasmusmc.nl 


\section{Introduction}

Congenital diaphragmatic hernia $(\mathrm{CDH})$ is a rare but severe anomaly with a mortality of approximately 20 $30 \%$. CDH is characterized by lung hypoplasia and pulmonary hypertension $(\mathrm{PH})$ which both increase morbidity and mortality in these infants [1]. The vasodilator nitric oxide can be used to reduce $\mathrm{PH}$, but its effect in patients with $\mathrm{CDH}$ is variable [2]. Therefore, sildenafil, a phosphodiesterase-5 inhibitor, is often added to enhance pulmonary vasodilation. However, efficacy and safety data of sildenafil in neonates are scarce, the variability in efficacy remains considerable, and the dose-response relationship is unclear [3]. Here, we describe a case of an infant with $\mathrm{CDH}$ and $\mathrm{PH}$ who received an unintentional 10 -fold overdose of oral sildenafil for 6 consecutive days.
Aside from the clinical effect, we describe how the measured sildenafil concentrations can be interpreted despite this absence of a clear target.

\section{Case Presentation}

A newborn girl (gestational age $38+1$ weeks, birth weight of $3.0 \mathrm{~kg}$ ) prenatally diagnosed with a left-sided $\mathrm{CDH}$ and an observed-to-expected lung-to-head ratio of $41 \%$ and an intrathoracic position of the liver, was born at the Erasmus Medical Center Sophia Children's Hospital in Rotterdam. After birth, she was intubated and admitted to the pediatric intensive care unit. The patient had no clinical symptoms of $\mathrm{PH}$ although the echocardiogram showed signs of $\mathrm{PH}$. On day 4 of life, the $\mathrm{CDH}$ was surgically corrected. In the following days, the patient deteriorated and the echocardiogram showed a closed ductus arteriosus, an enlarged right ventricle with a flattened septum and a right ventricu-

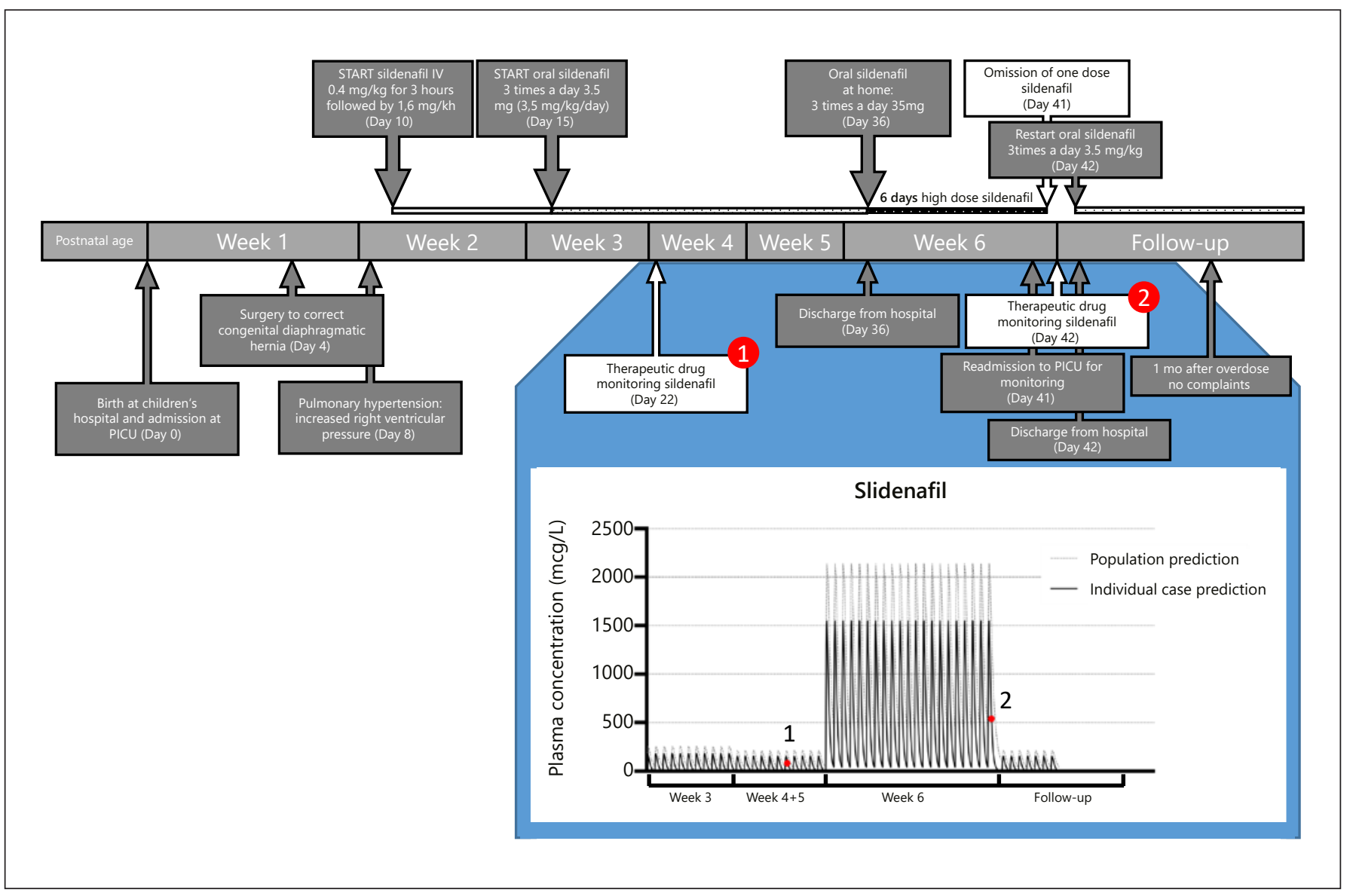

Fig. 1. Overview of events before and after a 10 -fold overdose sildenafil in the reported infant. The events that can be appreciated concern the dose adjustments, switched route of administration, collected samples for TDM (re-)admission and discharge, the population (dotted line) as well as the individual (solid line) predicted sildenafil concentration-time profile with a dot indicating the measured concentrations of sildenafil. PICU, pediatric intensive care unit; TDM, therapeutic drug monitoring; $\mathrm{PH}$, pulmonary hypertension. 
Table 1. TDM of sildenafil and active metabolite DMS measured in the reported young infant after oral administration

\begin{tabular}{lll}
\hline Date & PNA day 22 & PNA day 42 \\
\hline Dose sildenafil & $\begin{array}{l}3.5 \mathrm{mg} / \mathrm{kg} / \text { day intermittent oral dosing: 4:00 a.m., 12:00 p.m., } \\
\text { and 8:00 p.m. }\end{array}$ & $\begin{array}{l}35 \mathrm{mg} / \mathrm{kg} / \text { day intermittent oral dosing: 4:00 a.m., } \\
12: 00 \mathrm{p} . \mathrm{m} . \text { and 8:00 p.m. }\end{array}$ \\
\hline $\begin{array}{l}\text { Sildenafil and DMS } \\
\text { concentrations } \mathrm{mcg} / \mathrm{L}\end{array}$ & $\begin{array}{l}\text { Concentration measured at } 4.5 \mathrm{~h} \text { after administration of } 3.5 \mathrm{mg} / \mathrm{kg} \\
42 \mathrm{mcg} / \mathrm{L} \text { sildenafil }\end{array}$ & $\begin{array}{l}\text { Concentration measured } 4 \mathrm{~h} \text { after last administration } \\
\text { of } 35 \mathrm{mg} / \mathrm{kg} \\
521 \mathrm{mcg} / \mathrm{L} \mathrm{sildenafil} \\
393 \mathrm{mcg} / \mathrm{L} \mathrm{DMS}\end{array}$ \\
\hline
\end{tabular}

PNA, postnatal age; DMS, desmethylsildenafil; TDM, therapeutic drug monitoring.

lar pressure of $>2 / 3$ systemic pressure. Figure 1 shows an overview of the events. Because of this increased right ventricular pressure, sildenafil (Revatio ${ }^{\circledR}, 0.8 \mathrm{mg} / \mathrm{mL}$, Pfizer, New York, NY, USA) was prescribed intravenously on day 10 , starting with a loading dose of $0.4 \mathrm{mg} / \mathrm{kg}$ in $3 \mathrm{~h}$ followed by a continuous infusion of $1.6 \mathrm{mg} / \mathrm{kg} /$ day [4].

As the clinical situation of the patient improved, the continuous intravenous infusion was switched to an oral dosing regimen of $3.5 \mathrm{mg} / \mathrm{kg} /$ day divided into 3 doses (Sildenafil suspension, $1 \mathrm{mg} /$ $\mathrm{mL}, 100 \mathrm{~mL}$, Pharmacy A15, Gorinchem, The Netherlands). On day 36 of life, the patient was discharged home with a prescription for the same orally administered dosage of sildenafil. One bottle of sildenafil suspension (Revatio ${ }^{\circledR}, 10 \mathrm{mg} / \mathrm{mL}, 112 \mathrm{~mL}$, Pfizer, New York, NY, USA) was dispatched by the outpatient pharmacy including instructions, which would be enough to cover 3 months of therapy. However, when parents returned only one week later to collect a new bottle of sildenafil, the pharmacy discovered that the patient had received a 10 -fold overdose of $35 \mathrm{mg} / \mathrm{kg} /$ day sildenafil for the last 6 days. Apparently, at home, the parents administered the same volume per dose of the suspension of $10 \mathrm{mg} / \mathrm{mL}$ from the outpatient pharmacy as they had done on the ward with the suspension of $1 \mathrm{mg} / \mathrm{mL}$. That same morning the patient had developed watery diarrhea that lasted $1 \mathrm{~h}$, without other clinical symptoms. The infant had been well over the previous days; alert and active. Subsequently, the patient was readmitted to the pediatric intensive care unit for monitoring. At presentation we saw an alert, happy, somewhat pale infant with normal vital signs, such as heart rate and blood pressure. Further physical examination showed no other abnormality apart from some abdominal distension. Because of the mean estimated sildenafil half-life of $10.9 \mathrm{~h}$ in neonates with a PNA up to 7 days [5], together with the mild symptoms and the necessity to prevent subtherapeutic exposure, only one dose was omitted after which the original dosing regimen of 3 times per day $3.5 \mathrm{mg}$ was restarted. Overnight monitoring showed a normal heart rate of $130-140 \mathrm{bpm}$ and a varying blood pressure with a mean systole above $50 \mathrm{~mm} \mathrm{Hg}$. Also, all measured metabolic and hematologic values were normal (shown in see online suppl. Table 1; see www.karger.com/doi/10.1159/000514380 for all online suppl. material). Since the patient did not show symptoms of sildenafil overdosing besides diarrhea, the patient was discharged home after $16 \mathrm{~h}$. She continued to use sildenafil 3 times $3.5 \mathrm{mg}$ orally which she tolerated well despite diarrhea 1-2 times a day in the week that followed after the restart. No additional symptoms were reported at follow-up visits.

\section{Discussion}

This case describes a young infant who was exposed to an unintentional 10 -fold overdose of sildenafil for 6 days with only mild symptoms of overdosing. High-dose administrations of sildenafil have been discouraged because of a possible increased mortality risk and lack of information on the long-term risks [6]. Furthermore, little is known about the exposure of sildenafil in infants although clearance of sildenafil has been shown to mature rapidly during the first weeks after birth $[4,5]$. Plasma concentrations of sildenafil are often measured for safety reasons although a therapeutic range for sildenafil in neonates has not yet been established [2].

The use of sildenafil in neonates is associated with systemic hypotension, especially during a fast loading dose of intravenous sildenafil, and with gastrointestinal problems like diarrhea and vomiting, skin disorders, and edema [5]. In this patient, the only symptom was diarrhea, which appeared on the sixth day of sildenafil overdose. It is, therefore, likely to assume a causal relation between the overdose and diarrhea. Also, the contribution of DMS to this symptom cannot be ruled out while the diarrhea continued for 2 days after discontinuation of the overdose. However, this continuation of diarrhea can also be due to a slow recovery of the original damage to the intestinal epithelium by the overdose. All in all, it is unknown if these mild symptoms following a high exposure to sildenafil are representative, as no similar case has been reported yet.

Another possible explanation for the mild symptoms may be the relatively low concentrations of sildenafil in our patient compared to the population predicted concentrations following this dosing regimen. Namely, in our patient, plasma concentrations of $521 \mathrm{mcg} / \mathrm{L}$ sildenafil and $393 \mathrm{mcg} / \mathrm{L}$ DMS were measured. This concentration of sildenafil was approximately 10 -fold higher 
compared to earlier measured plasma concentrations of the therapeutic dosage in this patient (Table 1), both samples collected at $4 \mathrm{~h}$ after a dose. This concentration increase is in accordance with the 10-fold overdose that was administered. Next, the population pharmacokinetic model of Gonzalez et al. [7] was used for interpretation by predicting the individual sildenafil concentrationtime profile. Both the oral doses of $3.5 \mathrm{mg} / \mathrm{kg} /$ day as well as $35 \mathrm{mg} / \mathrm{kg} /$ day administered 3 times a day were simulated (Fig. 1). The population predicted concentrations over time are significantly higher than the individually predicted concentrations based on the measured sildenafil concentrations. This difference is in accordance with the described inter-patient variability of sildenafil clearance reported in the population PK model, which can be appreciated by the good individual fit though the measured concentrations in Figure 1. Despite the linear increase in our case, this should not be used as standard rule when an overdose of sildenafil occurs. Possibly, the presence of diarrhea led to faster passage of substances through the colon, thereby diminishing the absorption of sildenafil. The importance of intestinal absorption is supported by an in vivo study in rats indicated that the bioavailability of sildenafil was largely dependent on the gastro-enteral administration rate of the drug [8]. Variation in intestinal absorption can, therefore, contribute to the large inter- and intra-patient variability in sildenafil concentrations in infants, as already suggested by Ahsman et al. [9].

Blood samples after oral administration were taken 4.5 $\mathrm{h}$ after the last oral dose, instead of the more common used sampling time at $8 \mathrm{~h}$ after the last dose. This time of sampling is important for the interpretation of the sildenafil concentrations as after oral administration higher peaks and lower troughs in plasma concentrations will appear in comparison to continuous infusion. Therefore, generally trough levels after oral administrations are measured to determine efficacy and safety of sildenafil.

Although the increase of sildenafil concentration was directly proportional to the dose increase after the overdose, this was not seen for the metabolite DMS which increased only 5 -fold. Several aspects may contribute to the difference between the ratios; for example, the proportion sildenafil that is pre-systemically as well as systemically converted to DMS by CYP-enzymes may be different due to a possible nonlinearity in conversion capacity above a certain dosage; an increased renal elimination rate of DMS at time of overdose compared to therapeutic dosing.

The sildenafil and DMS concentrations, before and after the overdose, were in accordance with the predicted plasma concentrations in our simulations. This does not indicate that these concentrations are safe and can be used without caution. A sudden increase in sildenafil exposure could have potentially caused severe systemic hypotension, with the risk of shock with hypoperfusion of vital organs, such as the brain, heart, and kidneys [1]. In contrast to our case, these more severe events including asymptomatic tachycardia and priapism were seen in a case presented by Wills et al. [10] where an 18-month old infant ingested an overdose of sildenafil. Unfortunately, a clear toxicity cutoff for sildenafil has not yet been defined in literature. In absence of this cutoff concentration for toxicity, a patient should be clinically evaluated on his symptoms. Although clinical evaluation is most important after a sildenafil overdose, TDM can still be performed to determine the exposure upon presentation. Furthermore, sildenafil concentrations can be used as reference value in case the clinical condition worsened or would not have improved despite dose increase. With a second measurement, the clearance of sildenafil could be calculated and used to determine if longer observation of the patient and withholding of sildenafil is necessary.

Although the course of events was mild in this case, the overdose was unintentional and should have been prevented. The main cause of this incident was the dispensing of a sildenafil formulation from the outpatient pharmacy with a different concentration than the hospital pharmacy (10 vs. $1 \mathrm{mg} / \mathrm{mL}$, respectively). Therefore, we recommend that only one concentration per drug is used, at least within 1 institute.

\section{Conclusion}

This case demonstrates that an overdose of sildenafil in an infant may be relatively well tolerated. Furthermore, it shows how TDM can be used to relate sildenafil exposure to symptoms and support clinical decision-making after an overdose.

\section{Statement of Ethics}

Both parents gave written consent for publication.

\section{Conflict of Interest Statement}

There are no conflicts of interest. 


\section{Funding Sources}

The authors did not receive any funding.

\section{Author Contributions}

Dr. R.B. Flint conceptualized and designed the manuscript, drafted the initial manuscript and supervised data collection, critically reviewed, and revised the manuscript with special attention for important intellectual content. Laura E.J. Peeters, MSc and dr. Suzan C.M. Cochius-den Otter designed the manuscript, drafted the initial manuscript, collected and analyzed the data, and reviewed and revised the manuscript. Drs. Bregje C.M. Witjes and Saskia J. Gischler drafted the initial manuscript, analyzed the data, reviewed, and revised the manuscript. All the authors approved the final manuscript as submitted and agree to be accountable for all aspects of the work.

\section{References}

1 Mous DS, Kool HM, Wijnen R, Tibboel D, Rottier RJ. Pulmonary vascular development in congenital diaphragmatic hernia. Eur Respir Rev. 2018;27(147):170104.

2 Steinhorn RH. Neonatal pulmonary hypertension. Pediatr Crit Care Med. 2010;11(2 Suppl):S79-84.

3 Cohen JL, Nees SN, Valencia GA, Rosenzweig EB, Krishnan US. Sildenafil use in children with pulmonary hypertension. J Pediatr. 2019;205:29-34.e1.

4 Cochius-den Otter SCM, Kipfmueller F, de Winter BCM, Allegaert K, Tibboel D, Mueller A, et al. Pharmacokinetic modeling of intravenous sildenafil in newborns with congenital diaphragmatic hernia. Eur J Clin Pharmacol. 2019;76:219-27.
5 Mukherjee A, Dombi T, Wittke B, Lalonde R Population pharmacokinetics of sildenafil in term neonates: evidence of rapid maturation of metabolic clearance in the early postnatal period. Clin Pharmacol Ther. 2009;85(1):5663.

6 De A, Shah P, Szmuszkovicz J, Bhombal S, Azen S, Kato RM. A retrospective review of infants receiving sildenafil. J Pediatr Pharmacol Ther. 2018;23(2):100-5.

7 Gonzalez D, Laughon MM, Smith PB, Ge S, Ambalavanan N, Atz A, et al. Population pharmacokinetics of sildenafil in extremely premature infants. Br J Clin Pharmacol. 2019; 85(12):2824-37.
8 Oya Y, Watahiki D, Matsunaga M, Hirono K, Ichida F, Aoki M, et al. The pharmacokinetics of sildenafil may be affected by intestinal absorption rate in children admitted to the intensive care unit. Biol Pharm Bull. 2020; 43(12):1917-23.

9 Ahsman MJ, Witjes BC, Wildschut ED, Sluiter I, Vulto AG, Tibboel D, et al. Sildenafil exposure in neonates with pulmonary hypertension after administration via a nasogastric tube. Arch Dis Child Fetal Neonatal Ed. 2010; 95(2):F109-14.

10 Wills BK, Albinson C, Wahl M, Clifton J. Sildenafil citrate ingestion and prolonged priapism and tachycardia in a pediatric patient. Clin Toxicol. 2007;45(7):798-800. 